\title{
WILLIAM M. WHYBURN
}

\author{
$1901-1972$ \\ BY W. T. REID
}

William Marvin Whyburn was born in Denton County, Texas, on November 12, 1901, the son of Thomas and Eugenia Elizabeth (McLeod) Whyburn. He attended Bethel School, a small country school that went only through the ninth grade, and in the academic year 1916-1917 entered North Texas State College in the town of Denton, through the then existing "college qualifying examinations". In 1920 he entered the University of Texas in Austin, where he obtained the B.A. (1922), M.A. (1923) and Ph.D. (1927). His younger brother, Gordon Thomas, (for his obituary, see Bull. Amer. Math. Soc. 77 (1971), 57-72), for many years Chairman of the Department of Mathematics at the University of Virginia, was also a student at the University of Texas in the years 1921-1927, and they both received their Ph.D. degrees in June 1927. For the academic year 1927-1928, Whyburn was a National Research Fellow at Harvard.

In 1923, he married Marie Barfield, who was also a student at the University. To this union were born two children, Willa Marie in 1928, now Mrs. George Allen Austin, and Clifton Thomas in 1937, at present an Associate Professor of Mathematics at the University of Houston.

Whyburn's career as a teacher began at an early age. The period 1918-1920 was divided between work at North Texas State College and teaching in public schools in Denton County. It is to be remarked that one of his students at Little Elm School was Samuel Wilks, later to be Professor of Mathematical Statistics at Princeton for many years prior to his untimely death in 1964. After the receipt of his Master's degree in 1923, Whyburn's formal graduate study at the University of Texas was limited to summer sessions and the academic year 1926-1927; during this latter year he held the Louis Lipsitz Fellowship. For the academic year 19231924 he was Instructor at South Park Junior College, Beaumont, Texas, and in 1924-1925 an Assistant Professor at Texas A\&M College. His association with Texas Technological College in Lubbock, Texas, began as Associate Professor in 1925-1926, and for the period 1926-1928 he was listed as Professor, on leave from that institution.

In 1928 Whyburn went to the University of California at Los Angeles as Assistant Professor, and progressed through the ranks to Professor in 1938; he was Departmental Chairman in the years 1937-1944. In 1944 he became President of Texas Technological College, from which post he 
resigned in 1948, to begin his nineteen year association with the University of North Carolina in Chapel Hill as Kenan Professor of Mathematics and Departmental Chairman. His duties as Departmental Chairman were relinquished in the years 1956-1960, to serve as Acting Provost in 19561957, and as Vice President for Research in 1957-1960. In January, 1967, he retired from the University of North Carolina, and immediately was appointed Frensley Professor of Mathematics at Southern Methodist University in Dallas, a position which he held until June, 1970, when he returned to his home in Chapel Hill. Even after this "second retirement" he taught part-time at East Carolina University in Greenville, North Carolina, until his death by a sudden heart attack on May 5, 1972.

In his service to the mathematical community, for the years 1940-1942 he was a member of the Council of the American Mathematical Society, and an Associate Secretary of the Society in 1950-1953. He served on numerous committees of the Society, including the Subcommittee on Supply and Demand for Mathematicians, War Preparedness Committee, 1941. For the years 1938-1942 he was a member of the Committee for Section A of the A.A.A.S.; in 1948-1949 he was a representative of the American Mathematical Society on the Council of the A.A.A.S. He was First Vice President of the Mathematical Association of America for 1943-1945. In addition to the teaching positions listed above, he also taught in summer sessions at the University of Texas, the University of Virginia, and the University of California at Berkeley.

In December, 1943 he was elected a Corresponding Member of the National Academy of Peru, and in 1948 he was awarded the honorary LL.D. degree by Texas Tech. The year 1964 was spent at the University of London as an O.E.C.D. Senior Science Fellow.

I. His career as administrator. From all the schools at which he held administrative positions, former colleagues uniformly attest to Whyburn's high academic standards, and his intense devotion to the attainment of excellence. His period at UCLA was in its formative years, and he was one of the faculty leaders in the struggle to build the school into a major campus of the University of California. He served on numerous committees dealing with many facets of the university, some local as in the development of a strong Engineering School, others extramural as in matters concerning the association of UCLA with the University of California at Berkeley. During World War II, he was active in various related efforts. For the period 1941-1944 he was Chairman of the Supervisors Committee, Los Angeles Area, University of California, for Engineering, Science, Management War Training Programs. He served as Chief of the Operations Analysis Section of the Third Air Force in 1944. 
As President of Texas Tech he recruited able people, and provided leadership in advancing that school to a higher academic level and its recognition by such agencies as the American Association of Universities and the American Association of University Women. The institution also profited by Whyburn's contacts with government agencies, as reflected by the excellent support that was obtained for certain programs.

In the role of Departmental Chairman at the University of North Carolina, Whyburn added strength to the Mathematics Department through judicious appointments. As a member of the General Administration of the University he guided the structuring and administration of graduate study, and the reorganization of these functions on the three component campuses of the University. In particular, through his participation in basic negotiations between academic bodies and industrial corporations, as well as state and federal agencies, he played a major role in the development of a computation center which opened in 1959; his accomplishment in this project has been described by one of his former colleagues as "an administrative miracle". He was also active in the inception of the Research Triangle Institute, and in its early stages served as a member of its Board of Governors and its Executive Committee.

A modest man of a warm and effervescent nature and in general "low key" in procedure, he was a highly knowledgeable and astute administrator with an inner toughness that produced a rugged fighter whenever principle or quality was at stake.

II. His research. W. M. Whyburn's mathematical research was highly concentrated in the theory of ordinary differential equations, with a considerable portion dealing with second order differential systems. In this category the following specific topics may be isolated, although in many instances more than one area entered into a given treatment.

1. Boundary value problems, both linear and nonlinear, with boundary conditions involving multi-point and integral conditions.

2. Systems of difference equations, and the study of differential systems as limits of related difference systems.

3. General existence theorems, and functional properties of solutions.

4. Specific properties of Green's functions and Green's matrices.

$5 .^{\circ}$ Nonlinear matrix differential equations.

Throughout the whole of Whyburn's research on differential equations, there is evident the direct effect of earlier work by two of his professors in graduate school. Firstly, and of primary importance, was the work of his dissertation director, H. J. Ettlinger, whose own Ph.D. dissertation at Harvard was in the area of the Sturmian theory for second order differential systems in the Bôcher tradition. Secondly, of strong importance was 
the early work of M. B. Porter, who in 1902 first proved rigorously the passage to the limit from a second order linear homogeneous difference equation to a corresponding differential equation.

Whyburn's earliest publications, [1] and [2] of the Bibliography, were written as a graduate student; paper [1] summarized the results of his Master's thesis, and related results were presented in [2]. In particular, in [2] he established a perturbation theorem which for a differential system of suitable type provided a related differential system with no proper (characteristic) value in common with the given system; in other terminology, he determined a particular generalized Green's matrix with certain desirable properties as a function of the characteristic parameter.

The contents of Whyburn's dissertation [4] with certain modifications, were published as papers [5], [6] and [8]; in particular, [5] and [8] contained the results of $\S \S 1-8$ of his dissertation with only minor alterations, while [6] presented a decided extension of the results of $\$ 9$ of the dissertation on linear systems to some corresponding nonlinear systems. Already at this stage the treatment possessed the following properties, which were characteristic of much of his subsequent research on differential equations.

(i) The involved functions were assumed to be of such generality that solutions were in the Carathéodory sense; that is, absolutely continuous functions satisfying almost everywhere the differential equations.

(ii) For boundary value problems, the boundary conditions were multi-point and/or integral in character.

(iii) The differential equations were in general nonlinear, and in form illustrated by the second order system

$$
y^{\prime}=K(x, y, z ; \lambda) z, \quad z^{\prime}=G(x, y, z ; \lambda) y,
$$

in the scalar functions $y, z$.

(iv) For the study of oscillation phenomena for second order systems of the form (1), the involved hypotheses were weaker than in the classical Sturmian theory, so that in general there would exist non-singleton sets $\Lambda_{j}$ of proper (characteristic) values such that if $\lambda \in \Lambda_{j}$ then for a corresponding proper (characteristic) solution $\left(y_{j}, z_{j}\right)$ the function $y_{j}$ has $j-1$ zeros on the interval of consideration.

Another fact worthy of note is that in $[4, \S 9]$ and [6] Whyburn employed the polar coordinate substitution

$$
y(x, \lambda)=u(x, \lambda) \sin v(x, \lambda), \quad z(x, \lambda)=u(x, \lambda) \cos v(x, \lambda),
$$

to reduce the study of (1) to the consideration of the system

$$
v^{\prime}=K \cos ^{2} v-G \sin ^{2} v, \quad u^{\prime}=\frac{1}{2} u(K+G) \sin 2 v .
$$

Such a substitution is frequently referred to as a "Prüfer transformation", 
as its first published use in the derivation of results of the Sturmian theory for a linear homogeneous second order differential equation appears to have been that of H. Prüfer [Math. Ann., 95 (1926), 499-518]. However, as the author of this article had noted elsewhere, [Rocky Mt. J. Math. 1 (1971), 383-406; 384 in particular], the value of this method for Sturmian theory was independently promoted by Ettlinger, to whom Whyburn gives credit for suggesting the use of this transformation.

Researches with major emphasis on problems in Area $1^{\circ}$ were presented in papers [4], [5], [6], [26], [30], [35], [36], [39], [40], [41], [42] of the Bibliography. In particular, in the address $[\mathbf{2 6}]$ and the attendant paper [30], Whyburn introduced boundary conditions involving functional values at points of a denumerable set of the first species, as well as integral conditions. This type of general boundary condition persisted in many of his later considerations, notably in papers [39], [41] and [42].

The principal results of Whyburn in Area $2^{\circ}$ were presented in $[4$, $\S \S 2-5],[8]$ and [10]. In particular, for a system involving a first order vector difference equation with associated two-point end conditions, the analogue of a Green's matrix was introduced.

Papers [7], [12], [13], [14], [20], [25], [34], [41], and [45] deal primarily with problems in Area $3^{\circ}$ and related topics. In [7] Whyburn presented basic existence theorems for a differential system which in vector notation may be written

$$
y^{\prime}=f(x, y)+A(x, y) y,
$$

in the $n$-dimensional vector function $y(x)=\left(y_{i}(x)\right)$, where $f(x, y)$ denotes the $n$-dimensional vector function $\left(f_{i}(x, y)\right)$ and $A(x, y)$ signifies the $n \times n$ matrix function $\left[A_{i j}(x, y)\right](i, j=1, \ldots, n)$, together with associated boundary conditions of the form

$$
y_{i}\left(a_{i}\right)=\alpha_{i} \quad(i=1, \ldots, n),
$$

where $a=\left(a_{i}\right)$ involves in general different component initial values $a_{i}$ on a compact interval on the real line. In particular, in [12] it was established that the solution $y=y(x ; f, A, a, \alpha)$ of (3), (4) is in a certain sense a uniformly continuous functional of $f=\left(f_{i}\right), A=\left[A_{i j}\right], a=\left(a_{i}\right)$ and $\alpha=\left(\alpha_{i}\right)$. Papers [13] and [14] treat some functional equations and inequalities, the study being strongly motivated by certain types of differential functionals. Papers [20] and [25] are expository in nature, dealing in large measure with the work of Perron on the use of over and under functions to establish fundamental existence theorems for differential equations. In particular, [34] treats the concept of a minimax solution of a linear differential system, generalizing the notion of a maximum or 
minimum solution of such a system. This area was revisited in the last paper [45] of the Bibliography, written while Whyburn was at SMU.

As noted above, Whyburn's earliest publications [1] and [2] were in Area $4^{\circ}$. Some discussion of Green's functions and matrices occur in many of his later papers. Of particular importance in this area are portions of papers [26], [30], [39] and [42].

The principal results of Whyburn in Area $5^{\circ}$ were presented in papers [17] and [19]. In particular, for the special Riccati matrix differential equation $Y^{\prime}(x)+Y^{2}(x)=R(x)$, he established in [19] a generalization of the classical cross-ratio property of solutions of the ordinary scalar Riccati differential equation.

Paper [11] is unique among Whyburn's research on differential equations in that it is concerned with the qualitative nature of solutions of an equation of higher order than two. In fact, however, the basis for his treatment is an introduced coupled system of two linear second order equations, and in many cases the properties of solutions of the fourth order equation are derived from, or related to, similar properties of an associated second order equation. This paper, written during Whyburn's period at Harvard as a National Research Fellow, bears strong evidence of the influence of G. D. Birkhoff, to whom Whyburn expresses appreciation.

Paper [37] is the only publication of Whyburn concerned with a specific problem in "applied mathematics". It deals with some experimental firings of a .30-caliber flat-nosed projectile on four different target media, and the derivation of an associated empirical law of penetration with parameters the bulk density, porosity, flow permeability, and Rittinger's number for the target material.

The work of Whyburn outside the field of differential equations, but most intimately related, was that concerned with the theory of the Lebesgue integral via the approximation by step functions as introduced by F. Riesz, and presented in papers [15], [16] and [18].

The single paper [3] represents the work of Whyburn in complex function theory. Written while he was a graduate student, it also reflects the influence of M. B. Porter. In it Whyburn showed that, for a power series with unit radius of convergence, each point on the unit circle is a limit point of the zeros of the set of convergents as initially defined many years before by Porter. In particular, the result includes as a special instance the result of Jentzsch to the effect that for such a power series each point of the unit circle is a limit point of the zeros of partial sums.

Papers [9], [21] and [24] represent interests of Whyburn in topology. Paper [9], written while he was a National Research Fellow at Harvard, was occasioned by contact with Marston Morse and his theory of critical points. In particular, in this paper Whyburn showed that a certain type 
of functionally defined locus specifies a closed manifold in the sense of combinatorial topology. Later in [24] he returned to this topic to discuss conditions that a real valued function $u=f\left(x_{1}, \ldots, x_{n}\right)$ in a finite number of real variables must satisfy in order that the function generate a locus which is a cell, complex, or manifold. In particular, certain of his basic results were derived with the aid of a general implicit function theorem due to Hedrick and Westfall. Finally, in modern terminology, the result of the note [21] is that in a topological space, which is regular and generated by a family of neighborhoods satisfying the Hausdorff neighborhood postulates, a collection $F$ of closed sets has a nonempty connected intersection whenever at least one of the sets is compact, and any finite subcollection of at least two sets in $F$ has a nonempty connected intersection.

III. His teaching. Whyburn was interested in teaching at all levels, and according to one of his former colleagues he prided himself upon carrying a balanced load of courses at all levels from freshman to advanced graduate. In the classroom, one of his precepts was "give the student something that he can do", and he was always concerned with the development of the student's initiative. In supervising dissertation research, he carefully adapted his tactics to the individual student. Out of the classroom, he was sincerely concerned with the welfare of students and faculty, and was readily accessible to all.

His interest in the teaching of mathematics at the elementary level is evidenced by the books [29], [31], [38], [43] and [44] which he coauthored with Paul H. Daus, and the papers [27], [28], [32] and [33] of the accompanying Bibliography.

In spite of his heavy load of administration, at the University of North Carolina he directed the Ph.D. dissertations of the following twelve individuals: Anthony K. Hinds (1950), Leonard P. Burton (1951), Bertram M. Drucker (1953), Edward J. Pellicciaro (1953), Paul S. Herwitz (1954), Frank W. Stallard (1955), Tullio J. Pignani (1955), Garret J. Etgen (1964), Clay C. Ross (1964), Albert L. Deal, III (1965), Sandra G. Ness (1965), David W. Showalter (1965).

Sources. The author's acquaintance with W. M. Whyburn dated from 1926-1927, his first year as a graduate student at the University of Texas, and Whyburn's last year. Also, Whyburn was H. J. Ettlinger's first Ph.D. student, and the author was Ettlinger's second Ph.D. student. In addition to data provided by biographical sketches in American Men of Science and Who's Who in America, the above comments upon Whyburn's career as administrator are based upon letters and information received from some of his former colleagues at the various schools with which he was 
associated. Valuable attendant information was also provided by Whyburn's son Clifton, Lucille (Mrs. G. T.) Whyburn, and Professor Ettlinger.

\section{BIBLIOGRAPHY}

1. An extension of the definition of the Green's function in one dimension, Ann. of Math. 26 (1924), 125-130.

2. On the Green's function for systems of differential equations, Ann. of Math. 28 (1927), 291-300.

3. On the polynomial convergents of power series, Bull. Amer. Math. Soc. 33 (1927), 673-676.

4. Linear boundary value problems for ordinary differential equations and their associated difference equations, Dissertation, University of Texas, Austin, Tex., 1927.

5. Second order differential systems with integral and $k$-point boundary conditions, Trans. Amer. Math. Soc. 30 (1928), 630-640.

6. Existence and oscillation theorems for non-linear differential systems of the second order, Trans. Amer. Math. Soc. 30 (1928), 848-854.

7. On the fundamental existence theorems for differential systems, Ann. of Math. 30 (1928), $31-38$.

8. On related difference and differential systems, Amer. J. Math. 51 (1929), 265-286.

9. Non-isolated critical points of functions, Bull. Amer. Math. Soc. 35 (1929), 701-708.

10. On related difference and differential systems, Bull. Amer. Math. Soc. 36 (1930), 94-98.

11. On self-adjoint ordinary differential equations of the fourth order, Amer. J. Math. 52 (1930), 171-196.

12. Functional properties of the solutions of differential systems, Trans. Amer. Math. Soc. 32 (1930), 502-508.

13. A set of cyclically related functional equations, Bull. Amer. Math. Soc. 36 (1930), $863-868$.

14. Functional inequalities, Tôhoku Math. J. 33 (1931), 265-274.

15. A proof of the identity of the Riesz integral and the Lebesgue integral, Bull. Amer. Math. Soc. 37 (1931), 561-564.

16. On the integration of unbounded functions, Bull. Amer. Math. Soc. 38 (1932), 123-131.

17. Generalized Riccati differential equations, Tôhoku Math. J. 38 (1933), 447-450.

18. (with E. R. Hedrick), An application of the Dedekind cut notion to integration, Amer. J. Math. 55 (1933), 390-398.

19. Matrix differential equations, Amer. J. Math. 56 (1934), 587-592.

20. Existence theorems for ordinary differential equations, with special reference to their applications in physics, engineering and other fields, Univ. Calif., Los Angeles Publ. in Math. and Physical Sciences 1 (1935), 115-133.

21. A connectedness theorem in abstract sets, Bull. Amer. Math. Soc. 41 (1935), 365-366.

22. Raymond Garver, Nat. Math. Mag. 10 (1935), 72; List of articles and notes of the late Dr. Raymond Garver, ibid.,178-181.

23. Raymond Joseph Garver-in Memoriam, Bull. Amer. Math. Soc. 42 (1936), 163.

24. Complexes and manifolds represented by functions of real variables, Bull. Amer. Math. Soc. 42 (1936), 255-262.

25. Over and under functions as related to differential equations, Amer. Math. Monthly 47 (1940), 1-10.

26. Differential equations with general boundary conditions, Bull. Amer. Math. Soc. 48 (1942), 692-704.

27. The California subcommittee on mathematics, California J. Secondary Education 18 (1943), 292-293. 
28. Mathematics for production and war, Math. Teacher 36 (1943), 291-295.

29. (with P. H. Daus and J. W. Gleason), Basic mathematics for war and industry, Macmillan, New York, 1944.

30. Differential systems with general boundary conditions, Seminar Reports in Math., (Los Angeles) Univ. Calif. Publ. Math. 2 (1944), 45-61.

31. (with P. H. Daus), First year college mathematics with applications, Macmillan, New York, 1948.

32. Productive use of mathematical teaching manpower, Highlights of the Ninth Annual Mathematical Institute, Duke University, Durham, N.C. 1949, pp. 13-17.

33. Mathematics for the muddled, Highlights of the Twelfth Annual Mathematical Institute, Duke University, Durham, N.C., 1952, pp. 64-68.

34. (with L. P. Burton), Minimax solutions of ordinary differential equations, Proc. Amer. Math. Soc. 3 (1952), 794-803.

35. (with A. K. Hinds), A non-self-adjoint differential system of the second order, J. Elisha Mitchell Scientific Soc. 68 (1952), 32-43.

36. Note on a non-self-adjoint differential system of the second order, J. Elisha Mitchell Scientific Soc. 69 (1953), 116-118.

37. (with H. L. Morrison), Small caliber projectile penetration into brittle porous media, Meteoritics 1 (1954), 133-141.

38. (with P. H. Daus), Algebra for college students, Prentice-Hall, Englewood Cliffs, N.J., 1955.

39. Differential systems with boundary conditions at more than two points, Proc. Conference on Differential Equations, University of Maryland, College Park, Md., 1955, pp. 1-21.

40. A non-linear boundary value problem for second order differential systems, Pacific J. Math. 5 (1955), 147-160.

41. (with T. J. Pignani), Differential equations with interface and general boundary conditions, J. Elisha Mitchell Scientific Soc. 72 (1956), 1-14.

42. On a class of linear differential systems, Rev. Ci. (Lima) 60 (1958), 43-59.

43. (with P. H. Daus), Introduction to mathematical analysis, with applications to problems of economics, Addison-Wesley, Reading, Mass., 1958.

44. -_ Algebra with applications to business and economics, Addison-Wesley, Reading, Mass., 1961.

45. (with R. K. Williams), Complexes of differential systems, J. Differential Equations 11 (1972), 299-306.

Current address: Department of Mathematics, University of Oklahoma, Norman, Oklahoma 73069 